\title{
A Review on Smart IoT Based Farming
}

\author{
Hira Farooq ${ }^{1}$, Hafeez UR Rehman ${ }^{1,}{ }^{*}$, Anam Javed ${ }^{1}$, Mehnaz Shoukat ${ }^{1}$ and Sandra \\ Dudley $^{2}$ \\ ${ }^{1}$ Khwaja Fareed University of Engineering and Information Technology, Pakistan \\ Hirra.Farooq@yahoo.com; siddiqov@gmail.com; anamjaved9116@gmail.com; mehnazshoukat04@gmail.com \\ ${ }^{2}$ School of Engineering and Design, London South Bank University, London, UK \\ dudleyms@lsbu.ac.uk \\ *Correspondence: siddiqov@gmail.com
}

\begin{abstract}
Received: $12^{\text {th }}$ April 2020; Accepted: $15^{\text {th }}$ May 2020; Published: $1^{\text {st }}$ July 2020
Abstract: With the increase of world population, the availability of food to all inhabitants on globe is one of the significant challenges. These challenges need to be addressed by adopting innovative options to improve the soil capacity and the safety of environmental resources. The availability of real-time vital parameters related to farming such as moisture, temperature, weather, crops diseases and water management as well as predictive actions against the changes in parameters can provide great help to deal with these challenges. Internet of Things (IoT) is an evolving technology, has great potential to play and prevail its miraculous role in almost every field. IoT is a network of things that are capable of self-configuring network. The development of intelligent IoT based Smart farming is day by day getting its space in developed countries. It facilitates towards precision agriculture and turning the face of agriculture production. Subsequently, it is reducing spoilage of resources such as water, fertilizers, operating cost. The availability and development of cost effective smart miniaturized sensors, processors and communication technologies has made IoT based smart farming feasible. This paper aims to review most recent papers from year 2015 to 2020 in IoT based farming domain. The recent work is highlighted in terms of their scope, methodology and summarised in a table followed by discussion and analysis. The intention is to provide a platform for the future researchers to get a start towards a system with a single standard expert and complete autonomous assistive system.
\end{abstract}

Keywords: IoT; Smart Farming; Sensors; Cloud; Microcontroller; Machine Learning

\section{Introduction}

Farming is one of the oldest livelihoods in the history of mankind, and perhaps among those changing the most in today's world. Modern farmers face challenges like never before. With rising global population rates, changing nutritional demands, resource restraints, climate changes and enterprise competition, there is huge pressure on the agricultural industry to produce more food. A decline in total agriculture land utilized for food production has been observed over the past decades. Around 19.5 million square miles (39.47\% of the world 's land area) arable area was recorded for food production in 1991, which was reduced to approximately 18.6 million square miles $(37.73 \%$ of the world's land area) in 2013 [1]. The gap between demand and supply of food is becoming more significant and alarming with the passage of time.

Fortunately, innovations in technologies open new ways for the agricultural industry to meet this global challenge. Systems such as IoT sensors and big data analytics are offering chances to reinvent archaic farming practices, creating more cost-efficient processes that produce higher quantities of food with less strain on resources. IoT based smart farming system is built for monitoring the crop field with the help of sensors and automating the irrigation system. The aim is to increase the yields at maximum reducing water consumption and ultimately shift the traditional 
Agriculture to smart agriculture as well as Precision Agriculture (PA) based on automation and IoT technologies. IoT empowers numerous crops-oriented applications such as crop growth monitoring and selection, irrigation decision support, etc.

The famers can monitor the field's condition from anywhere anytime. In this paper recent diverse solution on IoT based smart farming systems are explored and presented. Aiming at compactly review the recent progress in the said domain to make an understanding of IoT based smart farming for the readers.

\section{Literature Review}

The system presented by [2] aims at adopting IoT in agriculture to exploit automation approach. Monitoring environmental factors plays a vital role to increase the production of the efficient crops. Two most important natural factors are considered in this study namely temperature and humidity of the field. Humidity sensor sense the water in air. The proposed system consists of temperature (TMP007) \& humidity (HDC1010) sensors and CC3200 single chip. The CC3200 is a cheap and faster programmable Wi-Fi MCU that enables true, integrated IoT development. If sensor sense abnormal reading, it transmits field information about the temperature, humidity to famers. A camera is linked with this chip to take images and send to farmers via MMS and subsequently the farmer will take appropriate action.

[3] Exploits the LM35 temperature sensor and soil moisture sensor that is deployed in field and used to monitor the water supplements. [3] proposed a system comprises of LM35 temperature sensor, moisture sensor, RPi 3 model B, IC 3208 converter, relay and a buzzer. A threshold value $2.4 \mathrm{v}$ is set for soil moisture; this may vary from crop to crop. If the value is found less than the set threshold $(2.4 \mathrm{v}$ in this case) the soil is classified as dry and signal is sent to turn on the water pump. Otherwise Soil is classified as wet and motor will be turned OFF. The data acquire from sensors are ingested to the cloud and can be accessible to farmer via his/her mobile/PC. The system let the farmer when to turn ON/OFF the water pump.

The aim of the investigation presented in [4] is to decrease the loss of water, labour and improve the productivity. Moisture sensor is used to sense the content of moisture in soil and sends moisture sensor information to Arduino. Moisture sensor is used to detect moisture in the soil. It works on the principle of open and short circuit. When the soil is dry the circuit behaves like an open circuit and close if the soil is wet. Wi-Fi module is used for communication to transmit data from sensor layer to the cloud. Data collected from moisture sensor is fed into Arduino and Arduino upload this information or values on cloud by using Wi-Fi. Threshold value is set according to the crop's need. Moisture level checked with respect to predefined threshold value. The threshold value is different for different crops. If the moisture value is less than the reference value pump is ON otherwise remains OFF. This helps in reduction of water usage.

[5] Proposed an innovative smart IoT based Stick equipped with temperature and moisture sensors, providing real time sensor data to famers on handheld device. The purpose of the study carried in [5] is to provide cost effective solution to increase the productivity. The stick equipped with Arduino Mega 2560 augmented with moisture sensor and temperature sensor to monitor temperature and moisture powered by solar panel as well as battery $(2200 \mathrm{mAh} ; 11.2 \mathrm{~V})$. The stick works as a plug and play manner, it starts transmitting live information to cloud through ESP8266 Wi-Fi module as it is placed into a field. The cloud data is accessible to a hand-held device like mobile cellular phone, tablet or laptop. The obtained data can easily be shared with some expert remotely via cloud. The arrangement assists famers by providing precise live feed of environmental temperature and soil moisture to increase the yield and take effective consideration of food production. The proposed system is tried on Live Agriculture fields giving high accuracy over $99 \%$ in data feeds.

Another investigation aimed at reduction of water consumption and subsequently maintains optimal ambient parameters by monitoring soil moisture condition, temperature and humidity in real time [6]. The system consists of WSAN component, cloud and user application [6]. WSAN consists of sink, sensor and actuator nodes. ZigBee is used as a communication technology, which is 
based on IEEE 802.15.4. A board with GPRS capabilities is used to transmit messages to cloud additionally responsible for getting irrigation related commands from cloud. Sink node acts like network controller while sensor and actuator nodes perform as router node or end node. Cloud is responsible for data dispensation, data saving and event detection for irrigation. User application serves as a user interface (UI) to view the location of network node and to access sensor data.

Soil features monitoring remotely is an emerging trend to enhance the crops productivity. An innovative approach by considering chemical properties of the soil has been applied in [7]. The work presented in [7] considered $\mathrm{pH}$ values in addition to temperature and moisture of soil. The soil characteristics are monitored through smartphones in real time to characterize the soil. The $\mathrm{pH}$ value of a solution is an indication of its acidity or alkalinity [8]. PH values range from 1-14, value less than seven indicates stronger the acidity [8] otherwise the soil is characterized as stronger in Alkalinity [8]. Antimony electrode is used to find $\mathrm{pH}$ value while temperature is determined by using DS18B20 sensor [7]. System is developed on STM32 Nucleo platform. The STM32 Nucleo board provides flexible way to users to build prototypes or smart systems. The collected sensor data is transferred to a client mobile phone via Bluetooth so that he/she can act promptly regarding fertilizer application. The proposed system has great potential to reduce the fertilization consumption and thus crop failure risk while maximizing the yields per acre.

A similar work is presented in [9] with a different infrastructure technology. Soil features for example $\mathrm{pH}$, temperature and humidity values are monitored. Based on the data, coming from various sensors, farmers cultivate their crops. The system consists of $\mathrm{pH}$, LM35 temperature and HH10D humidity sensors. Based on the soil and environmental properties the system provides suggestions to cultivate suitable crop in addition to real time monitoring. Sensors values are in the form of analog and to convert from Analog to digital MCP3008 microcontroller is used. General purpose input output (GPIO) act as interface between MCP3008 and ARM11. Sensor information sent to server via $\mathrm{Wi}$-Fi. Sensor values are optimized based on threshold values; and the decisions when to turn on and off water supply or fertilization are made automatically based on the set predefined values.

The framework presented in [10] provides real time access of soil humidity, moisture, temperature and water level to farmer via mobile application. The system architecture consists of NodeMCU, an open source or IoT platform that exploits the Lua scripting dialect based on ESP8266 SDK 1.4 and sensors to ambient parameters aforementioned. Water level sensor is responsible to monitor level of water in water reservoir, while LM35 is used to read the temperature. When the water level is below a certain threshold the farmer receives the information. Arduino microcontroller is used to connect and control all the sensors. ThingSpeak is used to develop an application around data accumulated by the sensors. It comprises constant data gathering, information dealing, receptions, applications, and modules [10]. All sensors are deployed and connected with Arduino. The sensors sense ambient data in real time and send to the organizer. Then farmer obtains the information on the cloud platform in detail. It has been observed that the time stamped information collected in cloud are helpful in anticipation regarding crop conditions and found significantly accurate.

A smart greenhouse system is designed by [11] aiming at real time monitoring of the key parameters remotely. The key parameters include temperature, humidity, moisture sensor, $\mathrm{CO} 2$ and light intensity. Based on the reference values of soil moisture, windows or doors of the greenhouse are rolled ON or OFF. Sensor data is collected and ingested to cloud. The sensors data at cloud is accessible to farmer any time at any place. The farmer can then control the mechanical door/window and water pump remotely.

Another study is carried out by [12] aimed at precise water supplement to crops. The system manages waters supplement by monitoring and analysis of ambient parameters that includes humidity and temperature, moisture and ultrasonic sensor. Ultrasonic sensor is used to monitor the level of water in the reservoir. The proposed system consists of PX28015 ultrasonic sensors, soil moisture sensor, DHT22/AM2302 Humidity and Temperature Sensor and ESP8266 microcontroller. Sensors connected to microcontroller are used to sense the amount of water as a combined effort. The system also determines the quantity of water required per day. A threshold value known as reference 
value is set. Motor pump will be ON/OFF each time when the amount of water is insufficient with respect to the reference value. A notification is sent to server and mobile via MQTT protocol.

The investigation carried out by [13] aims at automating the water management for farming. The IoT system used in this system comprises of moisture sensor mounted on ATMEGA328P Arduino Uno, NodeMCU, Adafruit server, relay and motor. NodeMCU is used to send sensor value to microcontroller. Adafruit server is used to store the sensor information. The soil moisture level correlate with the moisture sensor value in terms of voltage. If the soil moisture value causes the voltage level below $5 \mathrm{v}$, soil is classified dry, and a signal is sends to microcontroller (MC) to switch ON the water pump otherwise turns it OFF. In [13], the water management is carried out using an automated irrigation system.

Facilitating famers with real time data and other external parameters may enable him/her to make a prompt decision to manage time, cost and energy. Aiming this act, a smart system consists of IoT and WSN (Wireless Sensor Network) is discussed in [14]. Alongside the common ambient parameters like humidity, temperature soil moisture an additional ten days weather history report is also considered in this proposed system. A transceiver KIANI sensor nodes developed by SIXAB and IZU-WSN Research Lab, a processing unit comprises of Texas Instruments CC1101 Low-Power Sub1G, R Transceiver Processing unit outfits with Arduino Nano are used. The main unit is powered by $1200 \mathrm{mah} 3.7 \mathrm{v} \mathrm{Li}$-ion rechargeable battery. RPi3 is used as a gateway to collect sensors data and then transfer it to servers. The data stored in servers are made available to user via websites and mobile application. This remotely available data helps the user to make a prompt decision based on the information gave by the system.

[15] Proposed a system that monitors temperature, humidity, soil moisture and also senses the animal's movement like cows, dogs that may cause the disruption of fields. Screening temperature, moisture and motion of animals which may damage plants or fields are the main characteristics of this system. If there is any disparity, an alert notification will be transmited to farmer. System comprises of LM35 temperature sensor, humidity sensor, soil moisture sensor, Arduino UNO R3, ESP8266 Wi-Fi and GSM module. An android application is also established for user to interact with system. Arduino board is used as a gateway that sends information to cloud using Wi-Fi or GSM capabilities. Wi-Fi is used for updating sensed information to cloud and GSM based communication uses $2 \mathrm{G}, 3 \mathrm{G}$ and $4 \mathrm{G}$ services and is used to send alert message to famer cell phone. Farmer can also preset season and irrigation schedule for plants. The developed android app serves an interface, where farmer can interact and control or set irrigation scheduling according to season and programmed to send warning notifications. The system provides real time data along with weather reports, it is up to the farmer to take suitable action regarding switching ON/OFF the water pump against contemporary sensor values.

The main focus of the study carried by [16] is to increase agriculture productivity while minimizing the water consumption by using modernization techniques. This system introduces robots that are responsible for weeding, spraying, moisture detecting, bird and animal detection, warehouse management and smart irrigation. The system proposed by [16] comprises of node1, node2, node3 and a PC. Each node has different devices and sensors integrated with it. Node 1 equipped with GPS (Global Positioning System) which can be either controlled by computer or can be programmed. It is used for weeding, animal scaring and spraying. It consists of numerous sensors and devices such as ultrasonic obstacle sensor, camera, siren, cutter and sprayer. On other hand, Node 2 acts like a warehouse and consists of motion sensor, light sensor, humidity sensor, temperature sensor, room heater, cooling fan interfaced with AVR microcontroller. DHT11 a lowcost digital temperature and humidity sensor, sensors are used to detect humidity and temperature and if the sensed information exceeds the predefined value then cooling fan will automatically turn on and if the moisture value goes below the predefined value water pump gets turned on for temperature maintenance. While node 3 is a smart irrigation node which is used to screen and control water pump with the help of mobile application. ZigBee Module is used for communication among node 1 and node 2 . The system has two modes manual and automatic. In case of manual mode, the appliances will be turned on and off by the user while in automatic the appliances will be controlled based on threshold values. Temperature maintenance, humidity management and theft detection can 
be managed by smart warehouse system. Quantity of water can be controlled by an algorithm which maintains predefined values of temperature and soil moisture which can program into a microcontroller.

A robot based smart farming is also investigated by [17]. The robot is equipped with numerous sensors namely Thermo Hygro sensor, moisture, humidity, UV sensors, obstacle sensor, pH, PIR (Passive Infrared) and $\mathrm{CO} 2$ sensors. The wirelessly controlled robot is responsible for spraying pesticides, switching ON/OFF the motor and scaring the intruder such as birds or animals. The entire system comprises of Raspberry Pi 3 Model B, Solar plate, Wi-Fi modem, ZigBee, DC motor or spraying, LM380 audio speaker, water sprinkle, LCD and Camera. Robot is controlled as well as programmed using a remote Pc. Whenever robot sense a water shortage in the fields, it turns on the motor and when it senses Insects level movement it sprays pesticides.

The proposed system in [18] has numerous features like moisture and temperature sensing, irrigation facilities, intruders scaring, and GPS based remote monitoring and controlling. Sensors are interfaced with PIC16F877A microcontroller and wirelessly communication is achieved by using WiFi. The deployed sensors in the fields are connected to the microcontroller through RS232 protocol. System has two modes, manual mode and automatic mode. In manual mode upon analysing live data the farmer decides when to turn ON and OFF the motor. In automatic mode if sensed data exceeds threshold value, the buzzer is triggered, LED starts blinking, and a notification is sent to farmers via SMS and motor is switched OFF automatically. A detailed description is made available to farmer via an android application [18].

[19] Suggested IoT based system that facilitates the water management, crop monitoring and pesticides control. The system has two section agro logger and cloud interface with mobile application. The agro logger comprises of Arduino mini pro microcontroller board, five sensors (LM35 temperature sensor, moisture sensor, barometric pressure sensor, humidity sensor and light sensor) and actuators (consists of sprinkler irrigation valve, fertilizer controlling valve, humidity water spray valve) and these are all connected with Xively (an IoT open source platform enabling developers to connect sensor information to the Web and to shape their own applications on it) via Wi-Fi wireless communication module. Two modes of operations are used in this system; manual mode and auto mode. In manual mode user has to operate sprinkler irrigation valve, fertilization supplements and water spray valve and in auto mode these activities performed by the system. If the sensed information crosses the predefined value heater or fan will be turned ON/OFF. Water consumption is control via Android app in manual mode.

[20] Presented an intelligent irrigation system to control and screen the drips. Wireless sensors network based on ZigBee are used to monitor the water level. The sensors information transmit to cloud via gateway. The cloud data is available for the user via android application. Wireless monitoring of field irrigation system reduces human intervention and allows remote monitoring and controlling via phone. The approach adopted by [20] proposed a wireless sensor network to control and monitor the drip irrigation via mobile phone. The system helps to increase the quality and the quantity of field with minimum human involvement. It comprises of two wireless sensor nodes, Node1 and Node2. Each node has M116 water level sensor, LM393 moisture senor, DHT11 humidity and temperature sensor, Atmega328 microcontroller and a relay. Sensed values are sent to master node via ZigBee. Data stored and compare with reference value according to crop, Apache Tomcat HTTP web server hosted on cloud. Action sent to respective node and microcontroller, to control the relay to switching ON/OFF. In the manual mode, the proposed system will update the user with real time parameters of ground (fields) and the actions are let to the users to perform.

A smart framework [21] proposed to optimize the use of water and assist the famers to monitor their fields remotely without visiting their lands. System consists of two sensors, water level sensor and soil moisture sensor to monitor the moisture in soil. Sensed values transmit to ThingSpeak cloud via ESP8266 Wi-Fi module. Talkback is created that makes commands whether water the plants or not.

Alipio, $\mathrm{M}$ et al. proposed an approach in [22] aiming to control crops parameters and produce high Quality of crops using IoT based smart hydroponics farming. Hydroponics is a procedure of growing plants in water containing dissolved nutrients. Precision agriculture (PA) used to improve 
agriculture process by continuous plant monitoring and precise dealing that increased the quality, quantity, sustainability, and cost effectiveness of agricultural yield [22]. Hydroponics farm combined with sensors that gather and monitor plant parameters from the physical environment. The accumulated sensor data is then fed into Bayesian Network (BN) model data that classifies and predicts actuator levels [22]. A web interface is developed through a cloud platform to access remotely [22]. The reliability and improvements of proposed system outperformed the existing manual approach [22]. The proposed sensor network in [22] consists of five sensors that monitor different parameters required for plant growth namely $\mathrm{pH}$ level $(\mathrm{PH})$, electrical conductivity (EC), relative humidity (RH), light intensity (LI), and water temperature (WT). The sensors used in [22] are associated to RPi for correct data ensuring, the accuracy of each sensor is examined. Light bulb, humidifier and motor pumps also act as actuator to adjust light intensity, humidity, and draw water and liquid solution into the potholes respectively. Sensors, connected with Arduino Uno and RPi, gather data from the physical hydroponics farm environment. Subsequently, gathered information is transmitting to the cloud service platform (ThinkSpeak) through the Internet. Real-time series charts are also available for user via web interface for remote monitoring. The web interface provides automatic as well as manual options to set response against upcoming events. In the manual case, user has to choose manual adjustment based on user's knowledge, otherwise the system will use the prediction model created based on BN algorithm to control all the actuations of the farm. The BN model utilizes data constantly gathered for 27 days ( $24 \mathrm{~h}$ per day) which resulted to a total of 6,881 datasets (outliers omitted). From this available dataset, 5,505 instances are used as training set and the remaining 1,377 instances are used as testing dataset. They created the network classification model based on the 5,505 training dataset and gained $84.53 \%$ accuracy after model validation. Based on prediction, the automatic control crop yield was found better than manual control by $20-60 \%$.

An alternative and innovative approach presented by [23] is a model, AgriPrediction, aiming to increase the yield of agricultural via the application of WSN technology, mobile computing, and forecast strategies and helps the agricultural producer in the decision making about when to act, so the rancher can take helpful actions timely as soon as possible. The AgriPrediction model proposed by [23] is an end to end prototype model, not only obtaining real time data of soil moisture, temperature and air pressure, but also provide data prediction and details about battery health. The model consists of AgriMeasure, LoRaLPWAN (Low Power Wide Area Network) gateway and AgriPrediction Server. Agri Measures mainly responsible for data collection from sensors, processing (microcontroller such as Arduino) and LoRa transmitter. The process data is transmitted via LoRa to a LoRaLPWAN gateway, the gateway in turn transmits that data to AgriPrediction Server. The AgriPrediction Server uses Auto Regressive Integrated Moving Average (ARIMA) model for a predictive instrument or being classified as a scalable solution according to the necessities of crops. In case of any abnormalities against set threshold, an alarm event can be triggered and notifies the farmer via his/her cell phone. The AgriPrediction model applied on arugula cultivation and a gain of $17.94 \%$ were observed concerning leaf expansion and $14.29 \%$ in terms of weight in comparison with traditional cultivation technique.

A unique approach using multilevel parameter optimized feature selection algorithm incorporating with IoT and Extreme Learning Machine (ELM) is proposed in [24]. The impetus arose by realising the act that conventional judgmental analysis is not enough for selection of remedial options to counter the Plant Diseases (PD) and Nutrient Deficiency (ND) to enhance the fields [24]. To tackle such issues or yields enhancement while keeping the same resources, [24] established a remote monitoring of PD, ND alongside of other parameters such as humidity and temperature. These ready to view information will help to decide the quantity of fertilizer as imbalanced supply of fertilizer may end up with reduced yields as well as hazardous to health at consumers (human and animal) end [24]. The said system is separated into three phase's image processing, feature Subset Selection (SS) by using Genetic Algorithm (GA) and classification. In phase one, the images are captured via smart phone or any digital camera. Humidity and temperature sensors are interacted with Arduino and the images are transferred to Arduino via Bluetooth or Wi-Fi. The collected data along leaf image features points are stored in a database. Data normalization step carried out followed by colour and texture features extractions of the obtained images. In phase two GA is used 
for optimal SS prior to optimal features using multilevel parameters optimization techniques. Phase three deals with classification of PD and ND using ELM classifiers, performs accuracy and comparative analysis of classification previously carried out by ELM based on all extracted optimal features subset. The subsequently it generates reports to the end user, in this case farmers, about PD or ND classification and quantity of fertilizer to be supplied to specific field. The proposed model was applied against a standard high dimensional biomedical dataset as well as for real time leaf disease dataset which delivers $9.52 \%$ and $5.71 \%$ perfection in the classification accuracy by minimizing $58.50 \%$ and $72.73 \%$ features respectively. Simulation results validated that IGA-ELM is proficient to deal optimization, uncertainty and supervised binary classification problems with improved classification accuracy even though decreased the number of features.

The paper [25] focused on IoT based water management and conserving system so that water can be reuse in an effective manner in farming when required. Proposed framework consists of a plastic tray, soil, concrete and coriander seeds. Soil is placed on tray in a spilt way. At the bottom of the slopped farm, water gets together. When the plants absorb the water as much as needed, excess water move down the slopped farm. Excess water that is collected at the lower end of the farm reused by plants. Moisture sensor is placed in farm to detect the presence and requirement of water. Watering to the filed or farm based on moisture value (Predefined threshold value). Pump is installed coupled with moisture sensor in reservoir. When the water required for plants, moisture sensor value goes below the threshold and pump automatically waters the farm. In this way there is no need of manual control on the field and it reduces the farmer's burden. Water level detector, temperature and humidity sensor are also installed in reservoir and water level sensor helps to switch off the pump to control the wastage of water. Wi-Fi module is used for communication. Status of the farm is presented on LCD so farmer can view.

\section{Discussion and Analysis}

The approach presented in [2] uses (MMS) technology to send captured images to farmer to provide the information about temperature and humidity (in air) of fields. The use of MMS increases the cost per message transmission. System can be made smarter by inclusion of automatic decision support system. In addition to the above, automatic irrigation based on the analytics could made it even smarter and utilizes maximum potential of IoT.

[3] Uses Temperature and soil moisture sensors to monitor the water supplement. Historical data is used to control the quantity of water. Threshold value may be varying from crop to crop. Data acquisition is done by using IC3208. RPi is used as a gateway to transmit sensor data to cloud database via Wi-Fi. Totally automatic system also delivers real time data about temperature and moisture in soil of fields.

[4] Uses single sensor and the purpose of this system is to decrease the wastage of resources (water, labour) and increase yields. System presented in [3] [4] can be improved by adding humidity sensor (humidity in air), pH sensor, water level sensor and weather monitoring sensor, GPS technology for a geographical area identification. Data transfer resolution is not mentioned. Implementation of machine learning (ML) will further make the system smart and automate.

The IoT based smart stick is presented in [5], which is equipped with Arduino Mega 2560 augmented with moisture sensor and temperature sensor to monitor temperature and moisture powered by solar panel as well as battery $(2200 \mathrm{mAh} ; 11.2 \mathrm{~V})$. The action against real time data is let to the user to do it manually. The functionality of stick can be enhanced by adding more sensors such as $\mathrm{pH}$ or fertilization requirements, PIR or microbe level movement sensor and $\mathrm{CO} 2$ sensors for air quality and a GPS sensor for identifying the sector in the fields. Automatic relative appliance such as water pump, urea supplement actuation based on ML.

[6] Consists of WSAN based system to assess the need of irrigation for plants. To make the system more smart and intelligent ML can be incorporated with this.

An indoor IoT based farming is discussed in [7], where user is updated via smart phone about temperature, humidity and soil $\mathrm{pH}$ value. The sensor data are sent to client's mobile through Bluetooth. Again, the actions and decisions are let on to user side to decide upon viewing the instant 
data. The action could be the amount of fertilization and water supply to the field. The system scope only covers indoor farming and further the system has lack of automated decision support system.

The system presented in [9] monitors soil $\mathrm{pH}$, temperature and humidity. Framework can be improved by adding other sensors like water level and GPS sensors. ML techniques could be implemented to learn the activity pattern related to turning on and off actuators against changing ambient parameter and provide suggestions for crops monitoring.

The system presented in [10] is an approach to get real time access to soil humidity, moisture, temperature and water level via mobile phone application. ML could be implemented to lessen the farmer's burden and making suggestions and predictions based on the historical data in automated manner.

An IoT based smart framework to control the greenhouse agriculture is discussed in [11], which is used to observe the greenhouse parameters such as moisture content of soil, temperature, $\mathrm{CO} 2$ and light for bell pepper plant. Smart analytical design could enhance by prediction early in time.

The technique used in [12] is a precise water supplement approach for an optimal use of water reservoir. Again, the scope is limited to water management. The scope could be winded by adding other sensor and exploited the big data to get activity patterns and automate the actions against any change in the ambient parameters.

The investigation carried out by [13] aims at automating the water management for farming. The system is designed considering the controlled indoor test bed environment. Thus, the design issues will emerge if deployed in real fields. Aside from water management, monitoring the weather conditions, humidity and temperature coupling with machine learning will make it smarter. Further, the water management could be more sophisticated if considering droplets water supplement technology or sprinkles or smart drains instead of just turning on and off the water pump.

[14] Has proposed a smart framework based on wireless network using soil moisture, humidity and temperature sensors, $\mathrm{RPi} 3$ as a gateway. The downside of [14] lies, where the decision-making part solely rely on farmer sides it would be more efficient in future to make decision making process automated using big data analytics.

[15] Proposed an agriculture system in which farmer plan irrigation scheduling for his farm through an android application (which allows the farmer or end user to give input based on which the watering to be controlled). The presented system still relies on farmer to act upon the notification generated by the system to farmer's smart phone, it could be completely automatic based on previous farmer manual practice.

[16] Proposed a remote-control robot system that performs different tasks like weeding, spraying, moisture detection, animal and bird frightening, smart irrigation with smart control and smart warehouse management (temperature and humidity maintenance and theft detection). ZigBee is used for communication. GPS based remote control system that is presented in [16] can be improved by implementing machine learning.

Although system presented in [17] [19][20] are user friendly, smart and minimising labour and hence cost, ML should be implemented on this to make system intelligent.

The work carried out in [18] can also be enhanced by adding sensor for monitoring soil quality for precise fertilization supplement and further can be incorporated with ML for smart automation.

The main purpose of [21] is to reduce the farmer's effort and help them to monitor and irrigate their fields. How to perform a system in [21] it should be explained in the form of analytics. ML should implement for smart automation.

System presented in [22] consists of two modes manual and automatic based on sensors data. Modules like camera and Bluetooth technology can be integrated in the system and deep learning techniques can implemented for making the automatic mode more reliable and accurate in predictions. Bayesian model is extremely computationally costly. This even holds true when the network structure is already given. Furthermore, it tends to perform ineffectively on high dimensional data and prey to dimensionality curse.

[23] Proposed an AgriPrediction framework based on LoRA and ARIMA prediction model. The mobile application can be implemented for real time field monitoring to track crop status. Online ARIMA production gives good results but tests should be carried out on the basis of complexity and 
computational time of online and offline ARIMA. A real time monitoring using smartphone will be handier. Further, they system should consider more than one crops of different season.

[24] Proposed system is based on IoT and ELM (Extreme Learning Machine) for remote monitoring of Plant diseases (PD), nutrient deficiency (ND), humidity and temperature. The proposed model was applied against a standard high dimensional biomedical dataset as well as for real time leaf disease dataset which provides $9.52 \%$ and $5.71 \%$ improvement in the classification accuracy by decreasing $58.50 \%$ and $72.73 \%$ features respectively. Smart water management should also be considered, further the scope is limited to grape disease.

[25] Proposed system is about the management of water in farming and helps the farmers to reserve water for later use. This is only for small farms but it can be expand by using more number of sensors (moisture sensors, temperature and humidity sensors because a single sensor is used for certain distance) as we want more area we have to use more moisture sensors, temperature and humidity sensors, reservoir and higher voltage capacity motor pump.

This review highlighted, diverse approaches that have been adopted for a specific and limited objective and an improvement has been observed, but IoT based farming incorporation with big data has not yet been fully exploited. The fusion of IoT and big data has a great potential to address a global solution to the challenges of food, sustainable water management and other resources. Subsequently, this combination has capability to create expert systems that will be used by regular farmers as well as unexperienced users and yields maximum qualitative production. This will also create a community where users can delegate their successful experiences to each other by simply deploying their expert models and thus in turn promoting the farming. This paper is intended to lay a platform for future researchers to take the innovation one step ahead.

Following table shows the comparison between different reviewed investigations.

Table 1. Architecture framework comparison of IoT-base farming systems

\begin{tabular}{|c|c|c|c|}
\hline Reference & Technologies used & Pros & Cons \\
\hline$[2]$ & $\begin{array}{l}\text { Microcontroller: CC } 3200 \text { Chip, MCU } \\
\text { Communication Technologies: MMS, } \\
\text { Wi-Fi Module } \\
\text { Sensors: Camera, Temperature Sensor, } \\
\text { Humidity Sensor }\end{array}$ & $\begin{array}{l}\text { - Sends the information } \\
\text { about humidity and } \\
\text { temperature in air of field to } \\
\text { farmer } \\
\text { - Uses MMS technology to } \\
\text { send captured images }\end{array}$ & $\begin{array}{l}\text { - MMS adds extra cost } \\
\text { - No automatic support system }\end{array}$ \\
\hline [3] & $\begin{array}{l}\text { Microcontroller: RPi } \\
\text { Cloud server: Google Cloud } \\
\text { Sensors: Temperature Sensor, Soil } \\
\text { moisture Sensor }\end{array}$ & $\begin{array}{l}\text { - Water supply is controlled } \\
\text { based on the historical data }\end{array}$ & $\begin{array}{l}\text { - Data transfer resolution is not } \\
\text { mentioned } \\
\text { - No intelligent support system }\end{array}$ \\
\hline [4] & $\begin{array}{l}\text { Microcontroller: Arduino } \\
\text { Cloud server: Web server } \\
\text { Communication Technologies: Wi-Fi } \\
\text { Module } \\
\text { Sensors: Moisture Sensor }\end{array}$ & $\begin{array}{l}\text { - Reduced the wastage of } \\
\text { water and labor } \\
\text { - Threshold value is set to } \\
\text { control the water } \\
\text { supplement }\end{array}$ & $\begin{array}{l}\text { - Data transfer resolution is not } \\
\text { mentioned } \\
\text { - No intelligent support system }\end{array}$ \\
\hline [5] & $\begin{array}{l}\text { Microcontroller: Arduino } \\
\text { Cloud server: ThingSpeak } \\
\text { Communication Technologies: Wi-Fi } \\
\text { Module } \\
\text { Sensors: Temperature Sensor, Soil } \\
\text { Moisture Sensor }\end{array}$ & - Live monitoring facility & - Manually control \\
\hline [6] & $\begin{array}{l}\text { Microcontroller: MSP4305419A } \\
\text { Cloud Based WSAN, Communication } \\
\text { Technologies: ZigBee, GPRS } \\
\text { Sensors: Soil Moisture Sensor }\end{array}$ & $\begin{array}{l}\text { - Moisture measurement } \\
\text { - Weather forecast } \\
\text { - Irrigation based on the set } \\
\text { threshold value }\end{array}$ & - No automatic support system \\
\hline [7] & $\begin{array}{l}\text { Microcontroller: STM32L152RE } \\
\text { Communication Technologies: } \\
\text { Bluetooth } \\
\text { Sensors: pH Sensor, Temperature Senor, } \\
\text { Humidity Sensor }\end{array}$ & $\begin{array}{l}\text { - Indoor system } \\
\text { - Gives sensor information to } \\
\text { user on user's phone via } \\
\text { Bluetooth }\end{array}$ & $\begin{array}{l}\text { - Lack of automated decision } \\
\text { support system }\end{array}$ \\
\hline [9] & $\begin{array}{l}\text { Microcontroller: MCP3008 } \\
\text { Communication Technologies: Wi-Fi } \\
\text { Sensors: pH Sensor, Temperature Senor, } \\
\text { Humidity Sensor }\end{array}$ & $\begin{array}{l}\text { - Suggestion facility about } \\
\text { irrigation and fertilization }\end{array}$ & - No automatic support system \\
\hline
\end{tabular}




\begin{tabular}{|c|c|c|c|}
\hline [10] & $\begin{array}{l}\text { Microcontroller: Node MCU V3 } \\
\text { Cloud server: ThingSpeak } \\
\text { Communication Technologies: Wi-Fi } \\
\text { Sensors: Soil Moisture Sensor, } \\
\text { Humidity Sensor, LM35 Temperature } \\
\text { Sensor, Water Level Sensor }\end{array}$ & $\begin{array}{l}\text { - Real time access to sensors } \\
\text { data via thingSpeak }\end{array}$ & $\begin{array}{l}\text { - Lack of automated decision } \\
\text { support system }\end{array}$ \\
\hline [11] & $\begin{array}{l}\text { Microcontroller: Wi-Fi microcontroller } \\
\text { Cloud server: AWS } \\
\text { Sensors: Temperature Sensor, Humidity } \\
\text { Sensor, Moisture Sensor, CO2 Sensor, } \\
\text { Light Sensor }\end{array}$ & $\begin{array}{l}\text { - Controlling greenhouse } \\
\text { doors/windows based on } \\
\text { predefined soil moisture } \\
\text { value }\end{array}$ & - No intelligent support system \\
\hline [12] & $\begin{array}{l}\text { Microcontroller: ESP8266 NodeMCU } \\
\text { Communication Technologies: MQTT } \\
\text { Protocol } \\
\text { Sensors: Soil Moisture Senor, } \\
\text { Temperature Sensor, Humidity Sensor, } \\
\text { Ultrasonic Sensor }\end{array}$ & $\begin{array}{l}\text { - Controlling the actions of } \\
\text { motor pump(ON/OFF) } \\
\text { based on the threshold value } \\
\text { - MQTT protocol }\end{array}$ & - No automatic support system \\
\hline [13] & $\begin{array}{l}\text { Microcontroller: ATMEGA328P } \\
\text { Cloud server: Adafruit Server } \\
\text { Communication Technologies: Wi-Fi } \\
\text { Sensors: Soil Moisture Sensor }\end{array}$ & $\begin{array}{l}\text { - Controlling the actions of } \\
\text { motor pump(ON/OFF) } \\
\text { based on the threshold value }\end{array}$ & $\begin{array}{l}\text { - No sprinkles } \\
\text { - No smart drains } \\
\text { - No automatic support system }\end{array}$ \\
\hline [14] & $\begin{array}{l}\text { Microcontroller: Arduino } \\
\text { Sensors: Temperature Sensor, Humidity } \\
\text { Sensor, Soil Moisture Sensor }\end{array}$ & $\begin{array}{l}\text { - Data regarding sensors } \\
\text { stored on server and user } \\
\text { can view via GUI application }\end{array}$ & $\begin{array}{l}\text { - Decision making is rely on user } \\
\text { or farmer } \\
\text { - No automatic support system }\end{array}$ \\
\hline [15] & $\begin{array}{l}\text { Microcontroller: Arduino } \\
\text { Cloud server: Web server } \\
\text { Communication Technologies: Wi- } \\
\text { Fi/3G/4G, GSM capability } \\
\text { Sensors: Temperature Sensor, Humidity } \\
\text { Sensor, Soil Moisture Sensor, Motion } \\
\text { Sensor }\end{array}$ & $\begin{array}{l}\text { - Provide the facility to set } \\
\text { the irrigation scheduling } \\
\text { according season by using } \\
\text { android application } \\
\text { - Warning notification } \\
\text { facility }\end{array}$ & $\begin{array}{l}\text { - Manually control } \\
\text { - Lack of automatic support } \\
\text { system }\end{array}$ \\
\hline [16] & $\begin{array}{l}\text { Microcontroller: AVR } \\
\text { Communication Technologies: ZigBee } \\
\text { Sensors: Ultrasonic Obstacle Sensor, } \\
\text { Motion detector, Light Sensor, } \\
\text { Humidity Sensor, Temperature Sensor }\end{array}$ & $\begin{array}{l}\text { - Remote control robot } \\
\text { system } \\
\text { - System has manual and } \\
\text { automatic mode } \\
\text { - Automatic control is based } \\
\text { on threshold value }\end{array}$ & - No automatic support system \\
\hline [17] & $\begin{array}{l}\text { Microcontroller: R Pi } 2 \text { Model B } \\
\text { Communication Technologies: ZigBee, } \\
\text { Wi-Fi module } \\
\text { Sensors: Humidity Sensor, Obstacle } \\
\text { Sensor, pH Sensor, CO2 Sensor, Soil } \\
\text { Moisture Sensor, Thermo Hygro Sensor, } \\
\text { UV Sensor, PIR Sensor }\end{array}$ & $\begin{array}{l}\text { - Mobile robot controlling } \\
\text { spraying pesticides } \\
\text { - Switching ON/OFF the } \\
\text { motor and scaring the } \\
\text { intruder }\end{array}$ & - No automatic support system \\
\hline [18] & $\begin{array}{l}\text { Microcontroller: PIC16877A } \\
\text { Communication Technologies: Wi-Fi, } \\
\text { GSM Module } \\
\text { Sensors: Temperature Sensor, Moisture } \\
\text { Sensor, PIR Sensor }\end{array}$ & $\begin{array}{l}\text { - GPS based remote } \\
\text { monitoring } \\
\text { - System has manual and } \\
\text { automatic mode } \\
\text { - Automatic control is based } \\
\text { on threshold value }\end{array}$ & $\begin{array}{l}\text { - Lack of automated decision } \\
\text { support system }\end{array}$ \\
\hline [19] & $\begin{array}{l}\text { Microcontroller: Arduino Mini Pro } \\
\text { Communication Technologies: Wi-Fi } \\
\text { Module: } \\
\text { Cloud server: Cloud Intefrace, Xively } \\
\text { (central platform) } \\
\text { Sensors: Moisture Sensor, Temperature } \\
\text { Sensor, Humidity Sensor, Pressure } \\
\text { Sensor, Light Sensor }\end{array}$ & $\begin{array}{l}\text { - Facility of water } \\
\text { management } \\
\text { - Crop monitoring and } \\
\text { pesticides control } \\
\text { - System has manual and } \\
\text { automatic mode } \\
\text { - Automatic control is based } \\
\text { on threshold value }\end{array}$ & $\begin{array}{l}\text { - Lack of automated decision } \\
\text { support system }\end{array}$ \\
\hline [20] & $\begin{array}{l}\text { Microcontroller: Atmega328 Cloud } \\
\text { server: Apache Tomcat HTTP web } \\
\text { server } \\
\text { Communication Technologies: ZigBee } \\
\text { Sensors: Humidity and Temperature } \\
\text { Sensor, Moisture Sensor, Water Level } \\
\text { Sensor }\end{array}$ & $\begin{array}{l}\text { - Drip irrigation } \\
\text { - User can access android } \\
\text { data via android application } \\
\text { - System has manual and } \\
\text { automatic mode } \\
\text { - Automatic control is based } \\
\text { on threshold value }\end{array}$ & - No automatic support system \\
\hline
\end{tabular}




\begin{tabular}{|c|c|c|c|}
\hline [21] & $\begin{array}{l}\text { Microcontroller: Arduino UNO } \\
\text { Cloud server: ThingSpeak } \\
\text { Communication Technologies: Wi-Fi } \\
\text { Sensors: Water Level Sensor, Moisture } \\
\text { Sensor }\end{array}$ & $\begin{array}{l}\text { - Farmers can monitor their } \\
\text { fields remotely } \\
\text { - Irrigation control system }\end{array}$ & $\begin{array}{l}\text { - Lack of automated decision } \\
\text { support system }\end{array}$ \\
\hline [22] & $\begin{array}{l}\text { Microcontroller: Arduino } \\
\text { Cloud server: ThingSpeak } \\
\text { Sensors: Light Intensity, pH, Electrical } \\
\text { Conductivity, Water Temperature, } \\
\text { Relative Humidity }\end{array}$ & $\begin{array}{l}\text { - Hydroponic System } \\
\text { - Bayesian Network Model } \\
\text { - System has manual and } \\
\text { automatic mode }\end{array}$ & $\begin{array}{l}\text { - Extremely computationally } \\
\text { expensive model }\end{array}$ \\
\hline [23] & $\begin{array}{l}\text { Microcontroller: ATmega328 } \\
\text { Sensors: Temperature, Humidity, pH, } \\
\text { Luminosity, Solar Radiation, Soil } \\
\text { Electrical Conductivity, Plant } \\
\text { Chlorophy11 }\end{array}$ & $\begin{array}{l}\text { - LoRa Technology, ARIMA } \\
\text { Prediction Model }\end{array}$ & $\begin{array}{l}\text { - No mobile application for real } \\
\text { time monitoring }\end{array}$ \\
\hline [24] & $\begin{array}{l}\text { Microcontroller: Arduino } \\
\text { Communication Technologies: } \\
\text { Bluetooth or Wi-Fi } \\
\text { Sensors: Temperature, Humidity }\end{array}$ & $\begin{array}{l}\text { - Feature Subset Selection } \\
\text { Algorithm } \\
\text { - Improved Genetic } \\
\text { Algorithm- ELM classifier } \\
\text { (IGA-ELM) } \\
\text { - Feature Extraction } \\
\end{array}$ & $\begin{array}{l}\text { - Lack of water management } \\
\text { system }\end{array}$ \\
\hline [25] & $\begin{array}{l}\text { Microcontroller: Arduino } \\
\text { Communication Technologies: Wi-Fi } \\
\text { module } \\
\text { Sensors: Soil moisture sensor, } \\
\text { Temperature and humidity sensor }\end{array}$ & $\begin{array}{l}\text { - Water management and } \\
\text { water conserving system }\end{array}$ & - No automatic support system \\
\hline
\end{tabular}

\section{Conclusion}

In this paper, the IoT based farming is reviewed adopted by many researchers alongside technologies implementation and a brief analysis, advantages, and suggestions for enhancements are outlined. Farming issues related to precise and automated irrigation, fertilization to increase the yields to meet the challenges of food to an increasing world population with declining arable lands and thus minimize the human intervention and labour are major challenges faced by farmers in underdeveloped areas. In summary, the IoT based farming is yet not been exploited fully to address the challenges of food to an increasing world population with declining arable lands and thus minimize the human intervention and labour. IoT based farming incorporation with big data has potential to present a global solution to indoor as well as arable farming. IoT based farming is a broad development prospect of one of the highest technologies. It combines sensor, embedded computing, modern network as well as wireless communication and distributed information processing technologies to provide us with a new way to obtain enormous data to analyses deeply and automate the entire farming system for a better quality and quantity yields. The purpose of this paper is to succinctly review most recent techniques and technologies progress in IoT based farming to assist researchers to emerge a global solution of an IoT based Farming.

\section{References}

[1] Ayaz M., Ammad-Uddin M., Shari Z., Mansour A., and Aggoune E. (2019). Internet-of-Things (IoT)-Based Smart Agriculture: Toward Making the fields Talk. IEEE Access, 7, 129551-129583. doi: 10.1109/access.2019.2932609.

[2] Prathibha S., Hongal A., and Jyothi M. (2017). IOT Based Monitoring System in Smart Agriculture. 2017 International Conference on Recent Advances in Electronics And Communication Technology (ICRAECT). doi: 10.1109/icraect.2017.52.

[3] Rao R., and Sridhar B. (2018). IoT based smart crop-field monitoring and automation irrigation system. $2 \mathrm{Nd}$ International Conference on Inventive Systems and Control (ICISC). doi: 10.1109/icisc.2018.8399118.

[4] Mishra D., Khan A., Tiwari R., and Upadhay S. (2018). "Automated Irrigation System-IoT Based Approach". 3rd International Conference on Internet of Things: Smart Innovation and Usages (IoT-SIU). Available: https://ieeexplore.ieee.org/document/8519886 [Accessed 25 November 2019].

[5] Nayyar A. and Puri V. (2016). Smart farming. Communication and Computing Systems. 
[6] Sales N., Remedios O., and Arsenio A. (2015). Wireless sensor and actuator system for smart irrigation on the cloud. IEEE 2Nd World Forum on Internet of Things (WF-IoT). doi: 10.1109/wf-iot.2015.7389138.

[7] Na A., Isaac, W., Varshney S. and Khan, E. (2016). An IOT based system for remote monitoring of soil characteristics. International Conference on Information Technology (InCITe) - The Next Generation IT Summit on the Theme - Internet of Things: Connect your Worlds.

[8] Taylor C. NY:Kingfisher; 1st edition (September 15, 2000). The Kingfisher science encyclopedia, pp 186, New York.

[9] Ananthi N., Divya J., Divya, M., and Janani, V. (2017). IoT based smart soil monitoring system for agricultural production. IEEE Technological Innovations in ICT for Agriculture and Rural Development (TIAR). doi: 10.1109/tiar.2017.8273717.

[10] Lashitha Vishnu Priya P., Sai Harshith N., and N.V.K.Ramesh D. (2018). Smart agriculture monitoring system using IOT. International Journal of Engineering \& Technology, 7(2.7), 308. doi: 10.14419/ijet.v7i2.7.10603.

[11] Pallavi S., Mallapur J., and Bendigeri K. (2017). Remote sensing and controlling of greenhouse agriculture parameters based on IOT.

[12] Pernapati K. (2019). IoT Based Low Cost Smart Irrigation System. Retrieved 25 November 2019

[13] Lahande P., and Mathpathi D. (2018). IOT Based Smart Irrigation System. International Journal of Trend in Scientific Research and Development Volume-2(Issue-5), pp. 359-362. doi: 10.31142/ijtsrd15827.

[14] Kiani F., and Seyyedabbasi A. (2018). Wireless Sensor Network and Internet of Things in Precision Agriculture. International Journal of Advanced Computer Science and Applications, 9(6). doi: 10.14569/ijacsa.2018.090614.

[15] Sushanth G., and Sujatha S. (2018). IOT Based Smart Agriculture System. International Conference on Wireless Communications, Signal Processing and Networking (Wispnet). doi: 10.1109/wispnet.2018.8538702.

[16] Nikesh Gondchawar, Prof. Dr. R. S. Kawitkar. (2016). “IOT based smart Agriculture”, International Journal of Advanced Research in Computer and Communication Engineering, Vol.5, Issue 6, pp. 838-842.

[17] Krishna K., Silver O., Malende W., and Anuradha K. (2017). Internet of Things application for implementation of smart agriculture system. International Conference on I-SMAC (IoT in Social, Mobile, Analytics and Cloud) (I-SMAC). doi: 10.1109/i-smac.2017.8058236.

[18] Suma Sandra, S.Saranya, G.Shanmugapriya, and R.Subhashri. (2017). IOT Based Smart Agriculture Monitoring System. International Journal on Recent and Innovation Trends in Computing and Communication. Vol. 5, Issue 2.

[19] L. G., S. P., and V. R. (2017). Smart Agriculture System based on IoT and its Social Impact. International Journal of Computer Applications, 176(1), pp. 1-4. doi: 10.5120/ijca2017915500.

[20] Saraf S., and Gawali D. (2019). IoT based smart irrigation monitoring and controlling system. Retrieved 25 November 2019.

[21] Benyezza H., Bouhedda M., Djellout K., and Saidi A. (2018). Smart Irrigation System Based Thingspeak and Arduino. International Conference on Applied Smart Systems (ICASS). doi: 10.1109/icass.2018.8651993.

[22] Alipio M., Dela Cruz A., Doria J., and Fruto R. (2019). On the design of Nutrient Film Technique hydroponics farm for smart agriculture. Engineering in Agriculture, Environment and Food, 12(3), pp.315324. doi: 10.1016/j.eaef.2019.02.008.

[23] dos Santos U., Pessin G., da Costa C., and da Rosa Righi R. (2019). AgriPrediction: A proactive internet of things model to anticipate problems and improve production in agricultural crops. Computers and Electronics in Agriculture, 161, pp. 202-213. doi: 10.1016/j.compag.2018.10.010.

[24] Kale A., and Sonavane S. (2019). IoT based Smart Farming: Feature subset selection for optimized highdimensional data using improved GA based approach for ELM. Computers and Electronics in Agriculture, 161, pp. 225-232. doi: 10.1016/j.compag.2018.04.027.

[25] Anupama, H. S. et al. (2020) 'Smart Farming: IoT Based Water Managing System', International Journal of Innovative Technology and Exploring Engineering, 9(4), pp. 2383-2385. doi: 10.35940/ijitee.d1796.029420.

(C) 2020 by the author(s). Published by Annals of Emerging Technologies in Computing (AETiC), under the terms and conditions of the Creative Commons Attribution (CC BY) license which can be accessed at http://creativecommons.org/licenses/by/4.0. 